\title{
GIS TOOLS FOR ANALYZING ACCIDENTS AND ROAD DESIGN: A REVIEW
}

\author{
Romi Satria \\ PhD Student, Technical University of Madrid (UPM), Spain \\ María Castro \\ Associate Professor, Technical University of Madrid (UPM), Spain
}

\begin{abstract}
A significant unexpected outcome of transportation systems is road accidents with injuries and loss of lives. In recent years, the number of studies about the tools for analyzing accidents and road design has increased considerably. Among these tools, Geographical Information Systems (GIS) stand out for their ability to perform complex spatial analyses. However, sometimes the GIS, has been used only as a geographical database to store and represent data about accidents and road characteristics. It has also been used to represent the results of statistical studies of accidents but, these statistical studies have not been carried out with GIS. Owing to its integrated statistical-analysis capabilities GIS provides several advantages. First, it allows a more careful and accurate data selection, screening and reduction. Also, it allows a spatial analysis of the results in pre and post-processing. Second, GIS allows the development of spatial statistics that rely on geographically-referenced data. In this paper, several GIS tools used to model accidents have been examined. The understanding of these tools will help the analyst to make a better decision about which tool could be applied in each particular condition and context.
\end{abstract}

\section{INTRODUCTION}

Road traffic accidents are increasingly being recognized as a growing major issue, particularly in developing countries. They provide significant social and economic losses. The global status on the road safety 2015 of 180 countries reported that the worldwide road traffic deaths reach 1.25 million people per year. Additionally, the highest road traffic fatality rates occur in low-income countries (WHO, 2015).

Recently the numbers of studies on the tools for analyzing accidents and road design have increased considerably. Among these tools, Geographical Information Systems (GIS) stand out for their ability to perform complex spatial analysis. However, sometimes the GIS, has been used only as a geographical database to store and represent data about accidents and road characteristics. It has also been used to represent the results of statistical studies of accidents, but, these statistical studies have not been carried out with the (Kazmi \& Zubair, 2014; Chen, 2012; Loo, 2006; Liang et al., 2005). This paper reviews the accident studies made with GIS and presents several GIS tools used to perform spatial analysis of traffic accidents. 


\section{ACCIDENT ANALYSIS USING GIS}

Usually, researchers combine GIS and statistical models to evaluate risk of road accidents. For example, Li and Zhang (2007) show how GIS and advanced statistical models can be used. All data preparation, segmentation, and screening are performed in GIS. However, Bayesian analysis is done outside of any GIS platform. This approach is effective because it allows users to work with data in both tabular and spatial contexts, and to export and import data from a variety of formats. Another characteristic of this traditional approach is that it allows using different statistical models (Poisson, lognormal Poisson, negative binomial, etc.) independently of GIS (Shankar et al., 1995). Another researchers use GIS tools to carry out spatial analyses of traffic accidents.

Table 1 shows the main studies carried out for analyzing road traffic accidents with GIS. Note that the table is not intended to make a comparison among different methods or studies. The most used methods for spatial analysis of road traffic accidents are Moran's I statistic and Getis-Ord. In what follows, these studies are summarized attending to scope of the study, data and methodology used.

\subsection{Scope of the study}

There is a relatively high dispersion in the type of roads that are analyzed. Some researchers have analyzed both intersections and road segments (Erdogan et al., 2008; Castro et al., 2012; Ma et al., 2014). However, Moore et al. (2011) mentioned that intersections and roads were not analyzed together, because factors related to the accidents that occurred at junctions were different from factors on the road segment.

\subsection{Data Description}

The success of preventive actions depends on the traffic accident record analysis. Good quality, reliable and accurate data are needed in order to understand which factors affect for the road accidents. In addition, the spatial location of accidents is a critical aspect of accidents analysis.

\subsubsection{Area type}

Table 1 shows that eight studies analyzed urban areas, while six studies combined the data from rural, urban, motorway and suburban highways.

\subsubsection{Accident data in the analysis}

Several data, such as, road accidents, peak time of the accidents, pedestrians hit by buses, cars, scooters, and also, four years of accident data with individual differences and many other combinations, can be worked out (Rankavat \& Tiwari, 2013). Steenberghen et al. (2004) used dynamic segmentation in order to locate accidents. Dynamic segmentation makes possible to locate accidents data in a network, when the position relative to milestone is known, and other locational data are missing. Erdogan et al. (2008) stated that the records include the parameters collected in the accidents. Relevant parameters comprise those 
related to the accident time (date, hour), location (highway code, kilometer), driver's information (age, gender and alcohol consumption), environmental conditions (weather, lighting), type of vehicles involved and severity (property-damage only, number of people injured or killed). Some studies have also integrated the traffic and road geometry data in the analysis.

\begin{tabular}{|c|c|c|}
\hline Author and publication year & Area & Methodology \\
\hline Kim \& Nitz (1995) & Mixed & $\begin{array}{l}\text { Spatial tools describing the degree of spatial } \\
\text { concentration and analyzed spatial patterns of } \\
\text { different types of accidents. }\end{array}$ \\
\hline Steenberghen et al. (2004) & Urban & $\begin{array}{l}\text { Accident location, spatial clustering accidents } \\
\text { using Kernel density analysis. }\end{array}$ \\
\hline $\begin{array}{l}\text { Aguero-Valverde \& Jovanis } \\
\text { (2006) }\end{array}$ & Mixed & $\begin{array}{l}\text { Full Bayes hierarchical model with spatial and } \\
\text { temporal effects compared to a negative } \\
\text { binomial method for estimating annual county } \\
\text { level crash frequency. }\end{array}$ \\
\hline Erdogan et al. (2008) & Mixed & $\begin{array}{l}\text { Determination of hot spot with statistical } \\
\text { analysis (Kernel density analysis and Poisson) }\end{array}$ \\
\hline Erdogan (2009) & Urban & Moran's I statistic and Getis-Ord \\
\hline Gundogdu (2011) & Urban & $\begin{array}{l}\text { Hot pieces method to determine critical } \\
\text { stretches of road accidents and Probable } \\
\text { Hotspots to foresee the critical spots }\end{array}$ \\
\hline $\begin{array}{l}\text { Truong \& Somenahalli } \\
\text { (2011) }\end{array}$ & Mixed & $\begin{array}{l}\text { Severity index, spatial patterns of pedestrian- } \\
\text { vehicle crash data and pedestrian-vehicle crash } \\
\text { hot spots map. }\end{array}$ \\
\hline Budiharto \& Saido (2012) & Urban & $\begin{array}{l}\text { Accident blackspot: three methods (kernel } \\
\text { density estimation, cluster and outlier analysis) }\end{array}$ \\
\hline Çela et al. (2013) & Urban & $\begin{array}{l}\text { Accident spatial patterns using network K- } \\
\text { function and Network Kernel Density } \\
\text { Estimation (KDE) to find clusters and identify } \\
\text { the actual cluster locations. }\end{array}$ \\
\hline Rankavat \& Tiwari (2013) & Mixed & $\begin{array}{l}\text { Research the potential of utilizing GIS in } \\
\text { identifying pedestrian accident prone locations. }\end{array}$ \\
\hline Effati et al. (2014) & Urban & $\begin{array}{l}\text { Geospatial neuro fuzzy approach for } \\
\text { identification of hazardous zones }\end{array}$ \\
\hline Ma et al. (2014) & Urban & Quasi-Poisson model \\
\hline Tortum \& Atalay (2015) & Mixed & Moran's I statistic and Getis-Ord \\
\hline Yalcin \& Duzgun (2015) & Urban & $\begin{array}{l}3 \text { methods of spatial pattern analysis on a } \\
\text { network: Kernel density, nearest neighbor } \\
\text { distance, } \mathrm{K} \text { function }\end{array}$ \\
\hline
\end{tabular}

Table 1 Studies analyzing accidents using GIS 


\subsection{Methodology}

Table 1 shows the different methodologies that have been used for analyzing road accidents using GIS. Over the last two decades, the road accidents studies have been done by using GIS tools, for example, to examine the spatial distribution and pattern of their accidents (Kim \& Nitz, 1995; Gundogdu, 2010; Truong \& Somenahalli, 2011; Budiharto \& Saido, 2012), and to investigate the accident-prone locations (Rankavat \& Tiwari, 2013). In the recent years, the combination of GIS and statistical analysis is increasingly more used by many researchers for assessing the road accidents (Steenberghen et al., 2004; Erdogan et al., 2008; Erdogan, 2009, Ma et al., 2014; Tortum \& Atalay, 2015; Yalcin \& Duzgun, 2015; Benedek et al., 2016).

The most used methods are Moran's I statistic and Getis-Ord. These spatial tools are used to determine hot spots and analyze accident spatial phenomena. For example, whether there are locations where "cluster of accidents" or specific types of accidents occur. Section 3 provides a description of these GIS spatial tools.

In some cases, factor analysis is used. This analysis allows a small number of dimensions to explain most of the information in a large data set, if there is a sizeable redundancy. Tortum and Atalay (2015) made a factor analysis to identify variables that have a statistically significant relationship with the number of road accidents.

On the other hand, fuzzy logic has also been used. Effati et al. (2014) used a geospatial neuro-fuzzy approach for modeling hazardous locations. It was tested on a regional highway corridor and the hazardous locations found were compared with the existing black spots which were obtained using a statistical approach.

\section{SPATIAL ANALYSIS TOOLS}

In this section, spatial techniques in GIS used to analyze road traffic accidents are presented. Spatial analysis is used to geographically specify the locations where the crashes occurred, and to assess specific patterns of distribution through map visualization.

\subsection{Moran's I statistic}

Moran's I is a statistical tool that measures the spatial dependence of the accident location (Moran, 1948). MI also evaluates if the spatial pattern clusters are dispersed or random and also determines the level of concentration. According to Erdogan (2009), MI provides a single value of the spatial correlation and checking the clustering of the spatial pattern. Heavy locations of the proximity between the two points are often defined as the inverse of the distance between them. The attribute similarity severity index of two points is defined as the difference between each value and the value of the global average. Pirdavani et al. (2014) developed crash prediction models using geographically weighted regression. It was carried out by computing Moran's I for dependent and selected explanatory variables. The 
result revealed the necessity of considering spatial correlation when developing crash prediction models.

\subsection{Getis-Ord}

G Statistics are a family of statistics that has a number of attributes that make them attractive to measure the dependence of spatially distributed variables, especially when they are used in conjunction with MI. They deepen the knowledge about the processes that lead to spatial dependency and improve the detection of local 'pockets' dependence that may not appear when using global statistics (Getis \& Ord, 1992). The Getis-Ord statistic is used to identify hot spots of traffic accidents. A high value of the Getis-Ord statistic represents a group of high index value (hot spots), while a low value represents a low value of the index group. The hot spot analysis calculates Getis-Ord statistic for each feature in the data set.

\subsection{Kernel density}

Kernel Density Estimation (KDE) is a spatial data analysis of ArcGIS program. Budiharto and Saido (2012) measured Kernel Density for determining the risk spread of the accidents. The spread of risk can be defined as the area around the cluster where such risk may increase due to an accident. An analysis using KDE tool produces a raster output. Erdogan et al. (2008) used GIS as a management system for accidents analysis and determination of hot spots with statistical analysis (KDE and Poisson).

\section{CONCLUSIONS}

Many studies used GIS tools to show the location of accidents on a digital map and analyze the hot spots of traffic accidents. There is a great diversity in the number of accident data records and of the factors used. The number of accident data and the analysis of factors found depend largely on the availability of data.

Regarding spatial methods, the most commonly used are Moran's I and Getis-Ord statistic. Since Moran's I measures the spatial dependence of accident locations and clusters accident spots according to spatial patterns, it provides a powerful tool to study accident occurrence. On the other hand, the Getis-Ord statistic measures a single value of the spatial correlation and provides a measure of the clustering degree value in the spatial pattern.

Due to the great variety of methods and tools on GIS available in literature, researchers can perform many different highway safety studies and identify accident patterns on networks. The documentation of characteristics and limitations of the studies addressed in this review will help analysts to determine the best method for a particular study. 


\section{REFERENCES}

AGUERO-VALVERDE, J. and JOVANIS, P.P., 2006. Spatial analysis of fatal and injury crashes in Pennsylvania. Accident Analysis \& Prevention, 38(3), pp. 618-625.

BENEDEK, J., CIOBANU, S.M. and MAN, T.C., 2016. Hotspots and social background of urban traffic crashes: a case study in Cluj-Napoca (Romania). Accident Analysis \& Prevention, 87, pp. 117-126.

BUDIHARTO, U. and SAIDO, A.P., 2012. Traffic accident blackspot identification and ambulance fastest route mobilization process for the city of Surakarta. Jurnal Transportasi, 12(3).

CASTRO, M., PALETI, R. and BHAT, C.R., 2012. A latent variable representation of count data models to accommodate spatial and temporal dependence: Application to predicting crash frequency at intersections. Transportation Research Part B: Methodological, 46(1), pp. 253-272.

ÇELA, L., SHIODE, S. and LIPOVAC, K., 2013. Integrating GIS and spatial analytical techniques in an analysis of road traffic accidents in Serbia. International Journal for Traffic and Transport Engineering, 3(1), pp. 1-15.

CHEN, H., 2012. Black Spot Determination of Traffic Accident Locations and Its Spatial Association Characteristic Analysis Based on GIS. Journal of Geographic Information System, 4(6), pp. 608.

EFFATI, M., RAJABI, M., SAMADZADEGAN, F. and SHABANI, S., 2014. A geospatial neuro-fuzzy approach for identification of hazardous zones in regional transportation corridors. International Journal of Civil Engineering, 12(3), pp. 289-303.

ERDOGAN, S., 2009. Explorative spatial analysis of traffic accident statistics and road mortality among the provinces of Turkey. Journal of Safety Research, 40(5), pp. 341-351.

ERDOGAN, S., YILMAZ, I., BAYBURA, T. and GULLU, M., 2008. Geographical information systems aided traffic accident analysis system case study: city of Afyonkarahisar. Accident Analysis \& Prevention, 40(1), pp. 174-181.

GETIS, A. and ORD, J.K., 1992. The analysis of spatial association by use of distance statistics. Geographical Analysis, 24(3), pp. 189-206.

GUNDOGDU, I.B., 2011. A new approach for GIS-supported mapping of traffic accidents, Proceedings of the Institution of Civil Engineers-Transport 2011, Thomas Telford Ltd., pp. 87-96.

GUNDOGDU, I.B., 2010. Applying linear analysis methods to GIS-supported procedures for preventing traffic accidents: Case study of Konya. Safety Science, 48(6), pp. 763-769. 
KAZMI, J.H. and ZUBAIR, S., 2014. Estimation of vehicle damage cost involved in road traffic accidents in Karachi, Pakistan: a geospatial perspective. Procedia engineering, 77, pp. 70-78.

KIM, K. and NITZ, L., 1995. Spatial Analysis of Honolulu Motor Vehicle Crashes: I. Spatial Patterns. Accident Analysis \& Prevention, 27(5), pp. 663-674.

LI, L., ZHU, L. and SUI, D.Z., 2007. A GIS-based Bayesian approach for analyzing spatialtemporal patterns of intra-city motor vehicle crashes. Journal of Transport Geography, 15(4), pp. 274-285.

LIANG, L.Y., MA'SOEM, D.M. and HUA, L.T., 2005. Traffic accident application using geographic information system. Journal of the Eastern Asia Society for Transportation Studies, 6, pp. 3574-3589.

LOO, B.P., 2006. Validating crash locations for quantitative spatial analysis: a GIS-based approach. Accident Analysis \& Prevention, 38(5), pp. 879-886.

MA, L., YAN, X. and QIAO, W., 2014. A quasi-Poisson approach on modeling accident hazard index for urban road segments. Discrete Dynamics in nature and society, 2014, New York, NY.

MOORE, D.N., SCHNEIDER, W.H., SAVOLAINEN, P.T. and FARZANEH, M., 2011. Mixed logit analysis of bicyclist injury severity resulting from motor vehicle crashes at intersection and non-intersection locations. Accident Analysis \& Prevention, 43(3), pp. 621630 .

MORAN, P.A., 1948. The interpretation of statistical maps. Journal of the Royal Statistical Society. Series B (Methodological), 10(2), pp. 243-251.

PIRDAVANI, A., BELlEMANS, T., BRIJS, T. and WETS, G., 2014. Application of geographically weighted regression technique in spatial analysis of fatal and injury crashes. Journal of Transportation Engineering, 140(8), pp. 04014032.

RANKAVAT, S. and TIWARI, G., 2013. Pedestrian Accident Analysis in Delhi using GIS. Journal of the Eastern Asia Society for Transportation Studies, 10(0), pp. 1446-1457.

SHANKAR, V., MANNERING, F. and BARFIELD, W., 1995. Effect of roadway geometrics and environmental factors on rural freeway accident frequencies. Accident Analysis \& Prevention, 27(3), pp. 371-389.

STEENBERGHEN, T., DUFAYS, T., THOMAS, I. and FLAHAUT, B., 2004. Intra-urban location and clustering of road accidents using GIS: a Belgian example. International Journal of Geographical Information Science, 18(2), pp. 169-181.

TORTUM, A. and ATALAY, A., 2015. Spatial analysis of road mortality rates in Turkey, Proceedings of the Institution of Civil Engineers-Transport 168(6), Thomas Telford Ltd, pp. 532-542. 
TRUONG, L.T. and SOMENAHALLI, S.V., 2011. Using GIS to identify pedestrian-vehicle crash hot spots and unsafe bus stops. Journal of Public Transportation, 14(1), pp. 6.

WORLD HEALTH ORGANIZATION (WHO), 2015. Global status report on road safety. WHO Press. Geneva, Switzerland.

YALCIN, G. and DUZGUN, H.S., 2015. Spatial analysis of two-wheeled vehicles traffic crashes: Osmaniye in Turkey. KSCE Journal of Civil Engineering, 19(7), pp. 2225-2232. 